\title{
La primera década del conflicto en defensa de la Autonomía Local
}

\author{
Santiago A. Roura Gómez \\ Profesor Titular de Derecho Constitucional. Universidad de la Coruña \\ sargan@udc.es \\ Recibido: 12 de septiembre de 2011 \\ Aceptado: 18 de julio de 2012
}

\begin{abstract}
Resumen
El examen de la práctica del conflicto en defensa de la autonomía local en su primera década de funcionamiento refleja una escasa eficacia del mismo como medio para incrementar los poderes del gobierno local español. El trabajo examina las razones de esta escasa eficacia práctica y aboga por buscar, más allá de los remedios procesales, las soluciones a los retos que enfrenta el mundo local, como la dimensión y estructura organizativa del nivel local de gobierno, la financiación de las entidades locales y el funcionamiento de las instituciones locales desde el punto de vista del buen gobierno democrático.

Palabras clave

Conflicto en defensa de la autonomía local; gobierno local; autonomía local; Tribunal Constitucional español.
\end{abstract}

\section{First decade of constitutional conflict in defense of Local Autonomy}

Abstract

First decade of constitutional conflict in defense of local autonomy has not demonstrated its success in order to promote local Governments powers. This paper analyzes the causes of that and it promotes to seek solutions to local government problems beyond the Constitutional Court. Challenges facing local autonomy in Spain, as local Governments' adequate structure, financial coverage of local powers and the correction of democratic rules at local institutions are examined here.

Key words

Local government; local autonomy; Spanish Constitutional Court. 


\section{INTRODUCCIÓN}

La ley orgánica 7/1999, de 21 de abril, de reforma de la 2/1979, del Tribunal Constitucional (en adelante, LOTC), introdujo en nuestro Derecho hace algo más de diez años un proceso constitucional de tutela de la autonomía que la Constitución de 1978 reconoce a los entes locales: el conflicto en defensa de la autonomía local'. El primer conflicto de esta clase fue planteado, unos meses después, por la ciudad autónoma de Ceuta², y la primera sentencia constitucional en este tipo de procesos, la 240/2006, resuelve también aquel litigio. Sobre el nuevo conflicto local y al tiempo en que iba avanzando la tramitación parlamentaria de la ley orgánica que lo introdujo, publiqué en su momento un artículo 3 que ponía de manifiesto algunos problemas que, al menos en una primera aproximación teórica, el nuevo proceso planteaba, llegando a considerar contraria al sistema español de justicia constitucional una reforma que en la práctica venía a ampliar el número tasado de sujetos que, conforme a la Constitución, contaban con legitimación activa para la impugnación de normas con rango de ley pretendidamente inconstitucionales. Transcurrido tiempo suficiente para que los conceptos hayan madurado y, lo que es mucho más importante, recaídas ya las primeras resoluciones del Tribunal Constitucional en este proceso, incluidas dos sentencias (de los años 2006 y 2008), parece oportuno someter aquel primer examen, que pudo parecer severo en alguno de sus juicios, a una revisión que nos aproxime a la realidad teórica y práctica de este proceso y que ayude a despejar las dudas que su mera formulación estática planteaba. Atenderá la exposición, en primer lugar, a los datos estadísticos que ofrece la dinámica desarrollada por el proceso hasta el momento, a partir de la que se introducirán las conclusiones que arrojan esos datos y el examen de pormenorizado de las resoluciones que han recaído.

1 Conviene llamar la atención, aunque resulta tangencial a la cuestión principal que se plantea en este trabajo, sobre que la Ley Orgánica 1/2010, de 19 de febrero, de modificación de las Leyes Orgánicas del Tribunal Constitucional y del Poder Judicial ha establecido, en la nueva disposición adicional quinta 3, lo siguiente: "Las normas del Estado con rango de ley podrán dar lugar al planteamiento de conflictos en defensa de la autonomía foral de los Territorios Históricos de la Comunidad Autónoma del País Vasco, constitucional y estatutariamente garantizada". Están legitimadas para plantear estos conflictos las Diputaciones Forales y las Juntas Generales de los Territorios Históricos de Álava, Bizkaia y Gipuzkoa, mediante acuerdo adoptado al efecto. Los referidos conflictos se tramitarán y resolverán con arreglo al procedimiento establecido en los artículos 63 y siguientes de esta Ley". Es decir, y salvo mejor opinión, un verdadero conflicto frente a leyes, que no defiende la autonomía local, sino la autonomía foral, que se tramita como los conflictos de competencias pero que sólo pueden interponer los órganos de las provincias que conforman el País Vasco porque son las únicas que carecían de capacidad de reacción jurisdiccional frente a la ley del Estado que desconociese su autonomía foral reconocida en la disposición adicional primera de la Constitución. Entiéndase entonces que las Diputaciones Forales, pero no las Juntas Generales, de los Territorios Históricos de Álava, Bizkaia y Gipuzkoa tenían abierta, como Diputaciones, la posibilidad de interposición del conflicto en defensa de la autonomía local para defender ésta, y ahora tienen abierto un nuevo proceso constitucional (que se tramita como un conflicto -positivo, es de suponer- de competencias) frente a las leyes del Estado que a su juicio vulneren su autonomía foral, pues, como reza la exposición de motivos de la reforma de la LOTC “una cosa es la autonomía local, que también concierne, claro está, a las Diputaciones Forales en la medida en que ostentan las competencias propias de las Diputaciones Provinciales, y otra cosa distinta la autonomía foral”. Por otra parte, esta misma Ley Orgánica de 2010, al hacer inatacable, salvo por el Gobierno de la Nación y solo ante el Tribunal Constitucional, normas fiscales forales antes susceptibles de recurso contencioso-administrativo, ha provocado la reacción procesal de Ejecutivos y Legislativos de La Rioja y Castilla y León, dos Comunidades Autónomas de régimen fiscal común limítrofes con el País Vasco. Desde el punto de vista del análisis jurídico-constitucional importa la reforma porque ha operado una transformación en una parte del sistema de fuentes (o ha concluido una circunstancia en el orden de la impugnabilidad de las normas que ya se podía colegir del mismo): las normas fiscales forales aprobadas por los territorios históricos tienen la resistencia pasiva de las leyes postconstitucionales (solo se pueden impugnar ante la jurisdicción constitucional). Un primer y breve -pero no por ello menos incisivo- estudio de esta reforma puede verse en Pulido Quecedo, M. (2010), "Normas forales vascas", Actualidad Jurídica Aranzadi (798). El ATC 136/2010, de 5 de octubre, ha resuelto la acumulación de los recursos riojano y castellano-leonés.

2 Que hubo de hacerlo, recordemos, porque, al igual que a Melilla, se le vedó la posibilidad de interponer recurso de inconstitucionalidad, como inicialmente pretendía, sobre la base de considerar el Tribunal que las ciudades africanas, como consecuencia de la utilización del art. 144 b) de la Constitución para la aprobación de sus Estatutos, no son Comunidades Autónomas, sino ciudades con Estatuto de Autonomía, es decir, más que ciudades, pero menos que Comunidades. Los autos 201 y 202 de 2002, así lo establecieron. Sobre los pormenores de estos Estatutos puede verse Hernández Lafuente, A (1995) Estatutos de Autonomía para Ceuta y Melilla, Málaga, Algazara. Sobre el marco constitucional previsto para ambas localidades, que presentaba un conjunto de posibilidades diversas para su integración en la estructura territorial española, cfr., por todos, Ruipérez Alamillo, J (1991) Formación y determinación de las Co-munidades Autónomas en el Ordenamiento Constitucional español, Madrid, Tecnos, $2 .^{\text {a }}$ ed.

3 Roura Gómez, S. (1999) “El conflicto en defensa de la autonomía local”, Revista Vasca de Administración Pública, (55), 227-251 y, con casi idéntico contenido y para Latinoamérica, Roura Gómez, S. (2001) "El conflicto en defensa de la autonomía local en España", Revista Jurídica del Perú, (Año LI, 20) 1-21. Sin intención de ser exhaustivo, sobre el conflicto pueden verse con notable aprovechamiento, además de otras referencias que cito más adelante, los trabajos de Pérez Tremps, P (1998) La defensa de la autonomía local ante el Tribunal Constitucional, Madrid, Marcial Pons; Porras Ramírez, J. M. (2001) El conflicto en defensa de la autonomía local ante el Tribunal Constitucional, Madrid, Civitas; Naranjo de la Cruz, R. (2003) El proceso constitucional para la protección de la autonomía local en España y Alemania, Madrid, INAP-Diputación Provincial de Málaga. 


\section{UNOS CUANTOS DATOS SIGNIFICATIVOS}

Los datos estadísticos ${ }^{4}$ relacionados con el conflicto en defensa de la autonomía local ponen de manifiesto que, como parecía desprenderse del análisis puramente estático, la legitimación activa del conflicto dificulta extraordinariamente el acceso de los entes locales al proceso. Si, como se declaraba, una de las razones de su establecimiento residía en la oportunidad de conferir a las entidades locales facultades de autotutela en la jurisdicción constitucional, lo cierto es que las normas de acceso al proceso han constituido una severa limitación para que éste se ponga efectivamente (válidamente) en marcha. Así, desde la aprobación de la Ley Orgánica 7/1999 hasta el 15 de marzo de 2011 han ingresado en el Tribunal Constitucional 20 conflictos en defensa de la autonomía local, de los que, en la misma fecha, quedaban pendientes de resolución $9^{5}$. De los 11 fenecidos hasta entonces, solo 2 lo fueron por medio de sentencia (la 240/2006, de 21 de abril y la 47/2008, de 11 de marzo), sin que en ninguna de ellas el Tribunal Constitucional haya constatado la vulneración de la autonomía local alegada. Puede parecer, por lo tanto, que en un país con 18 cuerpos legislativos más 18 ejecutivos con capacidad legislativa delegada y, a veces, también de urgencia (potenciales vulneradores de la autonomía local) y 8.116 municipios, 43 provincias, 7 cabildos y 3 consejos insulares (potenciales demandantes, solos o unidos en el porcentaje adecuado) ${ }^{6}$ la interposición de 20 conflictos en defensa de la autonomía local en más de 10 años de existencia del proceso, no representa un índice muy elevado de litigiosidad local constitucional. Este escaso éxito -al menos numérico- del proceso tiene, a nuestro juicio, diversas explicaciones, de las que pasamos a dar cuenta.

\section{LAS DIFICULTADES EN LA LEGITIMACIÓN ACTIVA DEL CONFLICTO EN DEFENSA DE LA AUTONOMÍA LOCAL}

En primer lugar, pudiera suceder -y en efecto sucede- que las dificultades procedimentales para iniciar el proceso hayan supuesto una barrera excesivamente difícil de franquear para los sujetos legitimados, lo que, por lo demás, se apuntó ya desde el primer momento y las resoluciones recaídas hasta ahora han venido a confirmar. Existen, en este sentido, dos tipos de dificultades, en primer lugar las puramente numéricas y en segundo lugar las de naturaleza propiamente procedimental, que se refieren a los requisitos que deben acompañar a la demanda y al tiempo en que tales requisitos deben cumplimentarse y que, combinadas con las anteriores, explican en parte el escaso número de procesos planteados.

Por lo que se refiere a los condicionamientos puramente cuantitativos, las normas relativas a la legitimación en el conflicto responden, como se sabe, a dos grandes circunstancias: la de que los demandantes -municipios o provincias- resulten ser los destinatarios únicos de la norma con rango de ley que consideran vulnera su autonomía local y, de otra parte, la de que los demandantes supongan, al menos y siendo municipios, un séptimo de los que existan en el ámbito de aplicación de la ley, es decir, en principio -aunque es teóricamente posible trazar otros ámbitos más restringidos, como enseguida veremos- el conjunto del Estado o una Comunidad Autónoma y que cuenten, además, con un sexto de la población de ese mismo ámbito, o bien, siendo provincias, que representen al menos a la mitad de las existentes y cuenten como mínimo con la mitad de la población en ese ámbito de aplicación de la ley. ${ }^{7}$

Es evidente que para los casos de destinatario único esas dificultades de la puesta en marcha del proceso a que antes nos referíamos no existen. La mínima diligencia por parte de los entes locales interesados que resulten destinatarios únicos de las leyes pretendidamente vulneradoras de la autonomía local resolverá sin dificultad alguna los trámites del requisito mayoritario en su órgano plenario y de solicitud del dictamen del órgano consultivo.

La cuestión se complica, como se pudo vislumbrar de la mera lectura de la ley, cuando de lo que se trata es de aunar numerosas voluntades locales en un tiempo relativamente reducido y hacerlo además con respeto de

$4 \quad$ La fuente de los datos estadísticos que se utilizan en el presente escrito es el propio Tribunal Constitucional, (http://www.tribunalconstitucional.es/es/tribunal/estadisticas/Paginas/default.aspx y también http://www.tribunalconstitucional.es/es/tribunal/memorias/Paginas/ default.aspx. Las memorias anuales pueden consultarse también en formato papel. Con respecto al período de tiempo no cubierto por los datos hechos públicos por el mismo Tribunal la fuente es la elaboración propia.

5 Resultado de añadir a los 5 que figuran en la última Memoria del Tribunal Constitucional publicada cuando se redacta este escrito (de 2009), los 4 ingresados desde entonces, de los que solo consta la admisión a trámite de 3, según se concluye del examen de las bases de datos del BOE (resoluciones de la Secretaría de Justicia del Pleno del Tribunal Constitucional dando cuenta de las providencias de admisión a trámite) y de la consulta directa a los servicios del Tribunal Constitucional, a cuyos Letrados agradezco la paciencia demostrada en atender mis demandas de información estadística.

6 De la heterogeneidad de nuestra organización institucional de lo local da cuenta la propia necesidad de las aclaraciones que, con respecto a la legitimación genéricamente reconocida a municipios y provincias, debe hacerse en las disposiciones adicionales de la LOTC, para extenderla a las Islas (tres cabildos y dos consejos insulares, Disposición Adicional $3^{\text {a }}$. 1 y 2) y, en el País Vaso, a las Juntas Generales y a las Diputaciones Forales de cada Territorio Histórico, cuando el ámbito de aplicación afecte directamente a dicha Comunidad Autónoma (Disposición Adicional $\left.4 \cdot \cdot^{\mathrm{a}} \cdot 2\right)$.

$7 \quad$ Todo ello de conformidad con lo que establece el art. 75 ter. 1 de la LOTC. 
determinados formalismos, nimios tal vez desde la perspectiva de organizaciones administrativas de cierto peso específico, pero no tanto cuando de lo que estamos hablando es de micro municipios españoles, que son especie común en nuestra organización territorial local como es de sobra conocido. ${ }^{8}$

Un buen ejemplo de ese complejo de dificultades y de la problemática que plantean, en particular cuando la norma que pretendidamente vulnera la autonomía local es una ley estatal, lo ofrece lo sucedido con respecto a la ley 18/2001, de 12 de diciembre, general de estabilidad presupuestaria, refundida hoy en el Real Decreto-Legislativo 2/2007, de 18 de diciembre. Las limitaciones a la capacidad financiera de los entes locales que en ella se imponían motivó que muchos municipios decidiesen iniciar los trámites conducentes a la presentación de un conflicto en defensa de la autonomía local frente a la misma y, como era de esperar, los resultados de semejante procedimiento no fueron los apetecidos. A esta circunstancia hubo de referirse ya el Consejo de Estado, con ocasión de la emisión del dictamen de 20 de junio de 2002 relativo a este supuesto ${ }^{9}$, al manifestar el sinnúmero de problemas procedimentales detectados: certificaciones de acuerdos plenarios que aprueban iniciar los trámites del conflicto pero no dan cuenta de la mayoría obtenida en la sesión correspondiente, o que dan cuenta de una inferior a la absoluta requerida por la LOTC; acuerdos de órganos distintos al Pleno de la Corporación; certificaciones de los acuerdos en las que no se hace constar la norma frente a la que se va a plantear el conflicto y otras que no vienen expedidas por el Secretario General de la Corporación y acuerdos plenarios que resuelven la reacción procesal frente a la ley que, en fin, se adoptan antes de que haya sido objeto de publicación oficial. Con este antecedente en su tramitación no extrañará que el proceso acabara con los AATC 419/2003 y 46/2004 (que ratifica el anterior, recurrido en súplica), auténticas piezas de convicción, en mi opinión, de hasta qué punto el conflicto en defensa de la autonomía local es un instrumento de más bien escasa virtualidad práctica cuando de reaccionar frente a normas con rango de ley del Estado se trata. Y es que, pese a que el procurador de los tribunales que ostentaba la representación de los ¡1.185!10 municipios españoles que conformaban el litisconsorcio activo necesario en aquellos autos, solicitó -y obtuvo-en dos ocasiones del Tribunal Constitucional, la ampliación del plazo de 30 días que inicialmente se le había concedido para subsanar los numerosos defectos de las certificaciones de los acuerdos de planteamiento del conflicto, ni siquiera en los casi cuatro meses de que finalmente se dispuso fue posible acreditar la válida postulación de 86 de ellos, con lo que el auto acabó por inadmitir el conflicto y ordenar el archivo de las actuaciones.

La perseverancia de los municipios no tiene acogida en la resolución del recurso de súplica que se interpuso contra el primero de los autos citados, resuelto, como dijimos, por medio del ATC 46/2004. En el antecedente 14 c) de este último el propio Tribunal reconoce la dificultad que, especialmente en los municipios de menor entidad,

8 Los datos, por conocidos, pueden obviarse. Interesa, en todo caso y porque se conecta directamente con el asunto tratado en este trabajo, el parecer de Font i Llovet, T. (1997) “El recurso de protección contra la autonomía local” en Defensa de la autonomía local ante el Tribunal Constitucional, Madrid, Ministerio de Administraciones Públicas-Instituto Nacional de Administración Pública, p. 104. De que existía conciencia en el legislador de que estos requisitos se podían convertir en un serio problema da noticia la inclusión en la LOTC de una apelación a la posibilidad de que las asociaciones de entes locales auxiliasen a su cumplimiento en tiempo y forma, liderando de alguna manera la actividad preprocesal necesaria para una interposición correcta de la demanda. En todo caso, como afirmé en su momento, esa mención resulta absolutamente gratuita, e inaudita en una norma procesal constitucional. Tal vez, como indicó Sánchez Morón, M. (2001), “De los conflictos en defensa de la autonomía local” en Requejo Pagés, J. L. (coord.), Comentarios a la Ley Orgánica del Tribunal Constitucional, Madrid, Tribunal Constitucional, p. 1.201, su naturaleza era pedagógica, lo que casa a la perfección, por lo demás, con el tono paternalista que, a mi juicio, destila tantas veces la legislación dirigida a lo local.

9 Quizá interese recordar que el Consejo de Estado se había negado a tramitar la inicial solicitud del Ayuntamiento de Lleida (el de más población de entre los que pretendían recurrir) por no haber sido presentada con la mediación del Ministerio de Administraciones Públicas, como se prevé en el artículo 48.2 de la Ley 7/1985, de 2 de abril, Reguladora de las Bases de Régimen Local, introducido por la Ley 11/1999, de 21 de abril, precisamente como complemento de la reforma operada en la LOTC que estamos comentando. La intervención de idéntico órgano estatal, a cuyo través debía llegar la solicitud al Consejo de Estado en las solicitudes de dictámenes que municipios de una misma Comunidad Autónoma presentaban por conducto de la Presidencia de la misma, había sido declarada inconstitucional por la STC 214/1989. Esta resolución, en cualquier caso, lejos de defender la autonomía local, lo que protegió fue la posición de las Comunidades Autónomas -su Presidencia-, en cuyo papel de mediador en la tramitación de las solicitudes de dictámenes al Consejo se declaró ocupaba, mutatis mutandis, la misma posición que el Ministerio competente en Administraciones Públicas con respecto a las solicitudes que éste canaliza cuando las entidades locales impulsoras pertenecen a más de una Comunidad Autónoma. Una manifestación más, a mi modesto entender, de la preterición de los poderes locales como poderes verdaderamente autónomos en el ordenamiento español. Salvo que se considere -que todo es posible- que reconocer la capacidad de una ingente pluralidad de Ayuntamientos de acudir, ellos solos, ante el Consejo de Estado, sin pasar una suerte de trámite de introducción de embajadores ejercido por el Ministerio de la cosa pública territorial o por una Presidencia autonómica en su caso, socava los cimientos mismos de nuestra democracia y modelo de Estado, ante los indudables riesgos para el devenir territorial de España que semejante operación conllevaría. En fin, al parecer, aun estando presentes en la organización territorial desde tiempos del Imperio Romano, los municipios españoles no han alcanzado aún, a juicio del legislador orgánico del Consejo de Estado y del básico de régimen local, edad bastante para pedir dictámenes, preceptivos y no vinculantes, por sí mismos.

10 De acuerdo con el Registro de Entidades Locales, 1.158 municipios conforman un séptimo del total de los españoles, mínimo exigido por el art. 75 ter. 1 b) de la LOTC para la válida interposición del conflicto. Semejante exigencia numérica provocó, como destacamos en el texto, un importante número de defectos procesales, que, aún cuando concurriera una denodada y seguramente extenuante diligencia de la representación procesal municipal, acabó deparando algún error propio de este tipo de acciones multitudinarias puesto de manifiesto por el Tribunal Constitucional, como la identificación en la demanda de una cifra de municipios inferior a los, en principio, actuantes o que los demandantes estimaran precisa una cifra de corporaciones aún mayor de los 1.158 necesarios. Vid. FJ 2, párrafos segundo y tercero del ATC $419 / 2003$. 
existe para cumplir los requisitos de postulación que exige la LOTC, si bien niega que deba ser el propio órgano constitucional, como pretendía la parte actora, quien se dirija a las entidades locales con respecto a las cuales se observaban defectos de postulación en orden a requerirles su subsanación. Resuelve además, contestando a las alegaciones de la súplica, que la exigencia de que sea el fedatario público municipal -funcionario con habilitación nacional o quien haga sus veces- quien certifique el acuerdo plenario de interposición del conflicto deriva de la normativa básica de régimen local, que determina su existencia o los mecanismos para proveer la sustitución de sus funciones en todos los municipios españoles. Por ello, si bien el artículo 75 quater de la LOTC no lo especifica, en modo alguno puede reputarse vulneración del derecho a la tutela judicial efectiva la exigencia del Tribunal de que sea éste el medio de acreditar la existencia de un acuerdo del Pleno de la Corporación adoptado en tiempo y forma (FJ 3).

En relación con qué ha de entenderse por destinatario único de una norma con rango de ley y con el modo en que ha de procederse para despejar la fórmula matemática prevista en el art. 75 ter.1 b) y c), es decir, para hallar el número de entes locales y población afectados por la norma en cuestión que se requieren a la hora de conformar el litisconsorcio activo necesario para interponer válidamente la demanda, el Tribunal Constitucional ha entrado a considerar alegaciones de quien interponía el conflicto sobre la base de entender que una norma con rango de ley tenía, por razones materiales, aplicación más restringida que todo el territorio de una Comunidad Autónoma o del Estado, más allá del supuesto de las leyes que responden a la categoría de ley singular de destinatario único, como en principio se pudo pensar. ${ }^{11}$

En ocasiones los demandantes se identifican con el destinatario único de la norma legal. En otros casos, una pluralidad de demandantes -pero en porcentajes menores a los establecidos en la norma de legitimación si se referencia al conjunto del Estado o de una Comunidad Autónoma- sostienen que la ley resulta realmente de aplicación a un número determinado de municipios o de provincias, aunque la ley no los identificase expresamente, sino solo resultasen identificables examinando determinados preceptos de la misma. Así, el custodio constitucional ha entrado a valorar -aunque sea para rechazarlas- alegaciones de provincias y municipios que sostenían que una ley aparentemente dictada con pretensión de generalidad, era en realidad aplicable únicamente en un ámbito más restringido.

Los AATC 360 a 364/2005, dictados como consecuencia de la interposición por distintas Diputaciones Provinciales de sendos conflictos en defensa de la autonomía local frente al Real Decreto-Ley 2/2004, de 18 de junio, por el que se modifica la Ley 10/2001, 5 de julio, del plan hidrológico nacional, que dio lugar a la derogación de determinados trasvases de agua, resultan un buen ejemplo de la labor de individualización, caso por caso, a que aboca cada conflicto local.

El ATC 360/2005 tiene su origen en la demanda presentada por la Diputación de Almería, que se consideraba destinataria única de determinadas previsiones, ahora derogadas, de obras de infraestructuras previstas en el plan

11 El Tribunal ha dado así la razón a la tesis expuesta por García Roca, J (2000), “El nuevo conflicto en defensa de la autonomía local”, Justicia Administrativa, ( $n^{\circ}$ extraordinario “La reforma del régimen local”), pp. 17-18, quien ya advertía de la posibilidad de que los cocientes exigidos por la ley se refiriesen a un ámbito más restringido que todo el territorio estatal o autonómico. Otros conflictos cuya admisión a trámite ha sido acordada ya por el Tribunal Constitucional parecen responder también, aunque en estos casos de manera menos artificiosa, a la posibilidad de reducir los ámbitos de aplicación de las leyes frente a las que se interpone el conflicto y, por tanto, el número de entidades locales necesarias para hacerlo válidamente. Así, por ejemplo, por providencia de 27 de septiembre de 2010, el Tribunal Constitucional admitió a trámite el conflicto interpuesto por el Ayuntamiento de Covaleda (Soria) contra la Ley de Castilla y León 1/2010, de 2 de marzo, de declaración del Parque Natural de Laguna Negra y Circos Glaciares de Urbión (Soria), norma que afecta además a los municipios de Vinuesa y Duruelo de la Sierra, en la misma Provincia. Con una problemática semejante (reacción local frente a normas legales autonómicas que, por razones de especial protección ambiental, someten a severas limitaciones las capacidades de los Ayuntamientos en cuyos municipios se asientan las áreas protegidas)el Pleno del Tribunal admitió a trámite, en sendas Providencias de 15 de febrero de 2011, dos conflictos interpuestos separadamente, por los Ayuntamientos de Sant Antoni de Portmany (contra el art. 1 del Decreto-Ley de Illes Balears 1/2010, de 26 de marzo, de medidas urgentes relativas a determinadas infraestructuras y equipamientos de interés general y contra el art. 1 de la Ley de Illes Balears 10/2010, de 27 de julio, de medidas urgentes relativas a determinadas infraestructuras y equipamientos de interés general en materia de ordenación territorial, urbanismo y de impulso a la inversión) y de Santa Eularia des Riu (contra el mismo artículo de la ley citada en último lugar, lo que se explica porque el primer Ayuntamiento presenta el conflicto frente a la legislación de urgencia y también frente al texto de la ley producto de la transformación del Decreto-ley en proyecto de ley y el de Santa Eularia únicamente frente a esta última norma). Por último, responde también a esta posibilidad, confirmada por la práctica procesal que vamos a analizar en el texto, de estudiar caso por caso cuál es el ámbito de aplicación de las normas con rango de ley y, en consecuencia, obtener el cociente efectivo de municipios exigidos para conformar el litisconsorcio activo necesario del conflicto, la admisión a trámite, por Providencia de 27 de septiembre de 2010, del conflicto interpuesto por el Ayuntamiento de Torremontalbo contra la Ley $3 / 2010$, de 10 de marzo, del Parlamento de La Rioja, por la que se aprueba la alteración de los términos municipales de Torremontalbo y de Uruñuela. Importa señalar, en cualquier caso, que los tres ejemplos que recogemos en esta nota responden a la naturaleza de leyes singulares con varios destinatarios (aunque tasados, identificados o identificables) y además autoaplicativas (pues agotan sus efectos en su promulgación, sin necesitar en sentido estricto actos posteriores de aplicación, aunque estos puedan existir). Es decir, en todos los casos aquí reseñados aparece implicada una norma que responde al concepto estricto de ley singular, pero no al de ley singular de destinatario único, en cuyo caso, claro está, lo pertinente sería aplicar el aproblemático supuesto de legitimación contemplado en el art. 75ter 1 a) y no el 75 ter 1 b), como es el caso. Vid. Montilla Martos, J. A. (1994) Las leyes singulares en el ordenamiento constitucional español, Madrid, Civitas, pp. 97 y ss. 
hidrológico nacional. ${ }^{12}$ El Tribunal considera que el conflicto debe inadmitirse porque el carácter global de la planificación hidrológica, establecida sobre un sistema de cuenca, no queda desvirtuado por la existencia de una previsión de obras que afectaban a una única provincia. El Tribunal determina que el ámbito de aplicación de la concreta disposición impugnada afecta, además de al ámbito de la única Diputación Provincial demandante, también al de las provincias de Cádiz, Málaga y Granada, por cuyo territorio transcurren las aguas de las cuencas afectadas. Al no representar, por sí sola, la Diputación almeriense la mitad de las afectadas ni la mitad de su población, el Pleno resuelve la inadmisión del conflicto.

Algo semejante sucedió con los AATC 361 a 363/2005, que resuelven igualmente la inadmisión en relación con los conflictos interpuestos frente a determinados preceptos del mismo Decreto-Ley $2 / 2004^{13}$. La diferencia estriba en que en este caso, las tres Diputaciones valencianas presentan tres conflictos conjuntos aunque separados, no considerando ser los destinatarios únicos de la ley, sino considerando que, conjuntamente las tres Diputaciones, cumplen con los porcentajes fijados a la legitimación provincial del conflicto local en el art 75ter.1 c) LOTC. Siendo los conflictos presentados sustancialmente iguales, el Tribunal resuelve su inadmisión en los tres Autos referidos de contenido prácticamente idéntico también. En ellos el Tribunal, analizadas las disposiciones legales del plan hidrológico afectadas por la norma de derogación frente a la que se interpone el conflicto, llega a la conclusión de que su aplicación afecta no solo a las provincias comprendidas en la zona hidrográfica receptora del trasvase, sino a todas las comprendidas en el ámbito de toda la cuenca hidrográfica afectada (la del Júcar) que, de acuerdo con la definición de la misma contenida en la normativa que la crea, transcurre por las provincias de Teruel, Albacete, Cuenca, Tarragona, Alicante, Castellón y Valencia. No representando las demandantes -las tres citadas en último lugar- la mitad de las afectadas, la consecuencia lógica resultante es la inadmisión por incumplir las disposiciones de la LOTC en relación con el litisconsorcio activo necesario para interponer válidamente el conflicto en defensa de la autonomía local.

El Tribunal Constitucional ha vuelto a desarrollar esa peculiar labor de indagación de cocientes aplicables en virtud del artículo 75ter.1 LOTC en un conflicto interpuesto por once Ayuntamientos de Aragón -aunque solo ocho de ellos lo hicieran en tiempo y forma, de acuerdo con el FJ 2 del ATC 108/2010- frente a la ley aragonesa 10/2009, de 22 de diciembre, de uso, protección y promoción de las lenguas propias de Aragón. Los Ayuntamientos recurrentes sostenían que donde efectivamente se iban a aplicar las previsiones de la ley era en un número determinado de los municipios aragoneses (con determinadas peculiaridades lingüísticas ausentes en otros) con respecto a los cuales los demandantes cumplían los requisitos cuantitativos que establece la LOTC (un mínimo de un séptimo en número y de un sexto en población). La norma proporcionaba cierto margen a la elucubración sobre el particular, pues determina unas acciones de los poderes públicos u otras en función del grado de especificidad lingüística de las zonas en que, precisamente por ese motivo, divide el territorio de Aragón.

El Tribunal considera que, con el texto de la ley en la mano, esa concreción del ámbito territorial de aplicación de la ley, que habilitaría la presentación del conflicto por un número pequeño de municipios, no puede acogerse. Lo de menos es desgranar ahora las razones que conducen al Tribunal a su conclusión, lo importante es poner de manifiesto que el Tribunal nuevamente ha procedido a examinar si la norma legal, dictada con apariencia de generalidad, tiene aplicación en ámbitos territoriales inferiores al conjunto, en este caso, de la Comunidad de que se trata.

La cuestión no carece de importancia, porque invita a los municipios y a las provincias, a posicionarse en relación a la legislación que les afecta con una perspectiva distinta a la actual. Y es que, si el Tribunal estuvo dispuesto a desgranar la incidencia territorial del plan hidrológico y de la norma lingüística aragonesa con la finalidad de determinar el número de provincias y municipios afectados y poder así establecer los quantums del litisconsorcio activo necesario del conflicto local, ¿no debería estar dispuesto también a hacer lo propio con cada una de las leyes que, en función del sector sobre el que incidan, puedan considerarse de aplicación territorial limitada? A la luz de los precedentes de los que acabamos de dar cuenta, no parece que pueda haber ya otra respuesta a este interrogante que la afirmativa. Así las cosas, la casuística que va a generar el examen de la legitimación en el conflicto local resultará infinita, y conducirá al Tribunal Constitucional a evaluar la validez del litisconsorcio de municipios y provincias en función de delimitaciones tan distintas como ámbitos de legislación sectorial resultan imaginables. Así, por ejemplo, frente a una norma con rango de ley del Estado sobre instalaciones nucleares tal vez deba reputarse suficiente la legitimación de un séptimo de los 67 municipios españoles radicados en las zonas 1 de los planes de emergencia nuclear (situados en una circunferencia de un radio de $10 \mathrm{~km}$. con centro en una central nuclear) que

12 Concretamente el trasvase de agua desde la zona del Bajo Ebro del plan hidrológico de la cuenca del Ebro al ámbito del Plan Hidrológico del Sur.

13 En este caso, el trasvase de agua afectado por la derogación se producía desde la zona del Bajo Ebro del plan hidrológico de la cuenca del Ebro al ámbito del Plan Hidrológico del Júcar. 
representen un sexto de la población de los mismos. O, por ejemplo, frente a una norma legal, estatal o autonómica, estableciendo determinada disciplina en la costa ¿estará dispuesto el tribunal a considerar las normas numéricas de legitimación a partir exclusivamente del número de entes locales ribereños en el Estado o la Comunidad Autónoma de que se trate? Más aún: supongamos que en una norma autonómica sobre ordenación del territorio, aplicable en toda la Comunidad, existe una parte específicamente concebida para su aplicación en municipios costeros. El precedente que representan los Autos que acabamos de comentar parece poder ser invocado en orden a que el Tribunal Constitucional admita la legitimación municipal para recurrir esa fracción específica de la ley sobre la base de contabilizar los Ayuntamientos que, en esa Comunidad Autónoma, linden con el mar territorial. Es decir, la práctica del conflicto local ha propiciado una individualización ad casum de las normas de legitimación del conflicto, de tal modo que aquellas entidades locales que concluyan que una norma con rango de ley o una parte identificada de la misma pudiera tener una aplicación territorial limitada, aunque no se refleje expresamente en la ley esta circunstancia, siempre y cuando dicha argumentación sea deducible del ámbito sectorial que regule la norma, estarán habilitadas para la válida constitución del litisconsorcio activo necesario exigido. Cierto es que, si atendemos a los Autos en que se fundamenta nuestra conclusión, no parece que el Tribunal Constitucional esté dispuesto a facilitar la admisión, pero ello no le exonerará de adentrarse en un examen pormenorizado de una multiplicidad de supuestos de ámbitos de aplicación imaginables, como los que ya ha resuelto o los que hemos aventurado por vía de ejemplo.

Con todo, la práctica de estos primeros años de conflicto local ha venido a confirmar -ya fuera con ámbitos generales o específicos de aplicación de las leyes- lo dificultoso de la interposición del proceso y ahí, como decíamos, puede estar una parte importante de la explicación sobre el escaso número de intentados.

\section{LA EFICACIA PROCESAL DEL CONFLICTO EN DEFENSA DE LA AUTONOMÍA LOCAL}

Con la perspectiva que aporta el transcurso del tiempo y la dinámica procesal constitucional verificada hasta la fecha, cabe preguntarse en qué medida la introducción del conflicto local constitucional ha contribuido a la finalidad perseguida, es decir, dilucidar si la existencia del conflicto en defensa de la autonomía local ha permitido a los entes locales una mayor/mejor defensa de su posición en el marco del reparto vertical de poderes que la Constitución estableció.

Hace doce años concluimos, como había hecho parte de la doctrina y el propio informe del Consejo de Estado sobre el anteproyecto de reforma de la LOTC, que las exigencias de la Carta Europea de la Autonomía Local (CEAL a la que se invocaba como causa de la modificación legal, en el sentido de necesitar darle cumplimiento) de dotar a las entidades locales de mecanismos reactivos frente a las eventuales vulneraciones de su autonomía, ya se cumplían en nuestro ordenamiento, con instrumentos de carácter jurisdiccional además, aunque no de naturaleza constitucional. En la jurisdicción constitucional y frente a las leyes, los entes locales sólo podían ser heteroprotegidos, por así decirlo, por parte de órganos o fracciones de los mismos, tanto del Estado como de las Comunidades Autónomas, que sí estaban constitucional y legalmente legitimados para presentar recursos de inconstitucionalidad frente a normas con rango de ley que desconocieran el principio constitucional de la autonomía local. De hecho, esa heteroprotección funcionó desde los mismos comienzos de la actividad del Tribunal Constitucional, una de cuyas primeras resoluciones, y la primera que resolvió un recurso de inconstitucionalidad, la STC 4/1981, refleja precisamente esa circunstancia, toda vez que fueron 56 senadores quienes plantearon el recurso, cuyo objeto se ciñó al examen del Derecho local preconstitucional desde la perspectiva del principio constitucional de autonomía local. ${ }^{14}$

Pero que el nuevo proceso no resultase imprescindible para cumplir la CEAL no significa que su efectiva existencia no haya reportado utilidad a la protección de la autonomía de las entidades locales en un contexto que -como dijimos entonces y seguimos diciendo ahora- está mucho más implicado con la protección del nivel autonómico de autogobierno que con el nivel local. El conflicto en defensa de la autonomía local podría, en este sentido, haber servido para materializar esa máxima de sabiduría -que a veces los académicos llevamos demasiado

14 El primer recurso de inconstitucionalidad que resolvió el Tribunal Constitucional se convirtió, quizá no podía ser de otra manera, en un verdadero leading case, ya no solo en relación con el Derecho Constitucional Local español, sino con los límites del ejercicio de la jurisdicción constitucional misma, de la naturaleza de la Constitución y de los efectos de su promulgación sobre el Derecho heredado del régimen franquista. La relectura actual de esta resolución y algunas otras que la siguieron en aquella primera época de nuestra jurisdicción constitucional entonces recién rediviva, de los fundamentos que condujeron a los primeros fallos y de los razonamientos que se formularon como votos particulares, me mueve a recomendar a los más jóvenes juristas de hoy a aventurarse entre sus líneas. Un ejercicio fecundo susceptible de convertirse en un íntimo homenaje a una institución que, aunque siempre debemos someter a un riguroso examen en su trabajo, ha sido situada en los últimos tiempos en una incómoda posición, que le ha granjeado duras y no siempre justas críticas, teniendo en cuenta que creo no equivocarme si proclamo que el Tribunal Constitucional -y quienes han trabajado en él, en diferentes puestos, en los últimos 30 años- ha realizado una labor por la consolidación del Estado Democrático de Derecho en España que pocas instituciones han sido capaces de emular, al menos en la permanencia de su tarea y en la discreción con que, generalmente, se ha verificado. 
lejos- que afirma que lo que abunda no daña. Sin embargo, nuevamente el análisis de la jurisprudencia conduce a concluir otra cosa. $Y$ es que si algo ha venido a demostrar la práctica jurisdiccional que hasta ahora ha propiciado el conflicto es su nula virtualidad en el terreno de la protección de la autonomía local frente al legislador. Como veremos, ya haya sido en sentencia (solo en dos ocasiones hasta el momento), ya en los autos recaídos, el Tribunal Constitucional nunca ha encontrado fundamento bastante en las demandas de los conflictos locales que han logrado superar los obstáculos procesales a su interposición para acoger las tesis de las entidades locales demandantes.

Esa nula eficacia probada hasta el momento de los procesos correctamente interpuestos, en unión de la trabajosa actividad preprocesal, está también, a mi juicio, detrás del bajo número de conflictos en defensa de la autonomía local interpuestos en estos años, funcionando como elemento disuasorio ante los potenciales demandantes.

En todo caso y a decir verdad, buena parte de esa nula eficacia procesal demostrada hasta el momento por el conflicto puede residir en la misma esencia del instrumento, en su naturaleza de conflicto frente a leyes. Ya se apuntó en su momento que las amenazas a la autonomía local no provienen necesariamente de los textos legales; que la autonomía de los entes locales no necesariamente se cercena en la letra de la ley, en lo que la ley dice, sino, muchas veces, en lo que la ley ni dice, ni hace y en lo que la ley, con lo poco que dice o hace, permite que luego haga quien la ejecuta. $Y$ es que, al ser un proceso frente a normas que, por su propia naturaleza, y salvo los supuestos de leyes singulares de que ya hemos dado cuenta, gozan de un elevado grado de abstracción y generalidad en su formulación (las leyes), su virtualidad solo es susceptible de rendirse allí donde, con la mera lectura de un precepto legal, pueda concluirse que se ha vulnerado la autonomía local. Y he aquí, probablemente, donde reside la mayor debilidad del conflicto en defensa de la autonomía local como mecanismo de protección de los entes locales: en que las amenazas a lo local rara vez se desprenden del tenor literal de las disposiciones legales, aunque puedan estar amparadas en éstas.

La práctica procesal del conflicto arroja ejemplos que, entiendo, vienen a probar esta afirmación. Así, cuando 36 municipios riojanos interpusieron el conflicto frente a determinado precepto de la Ley de La Rioja 5/2008, que daba nueva redacción a la ley de ordenación del territorio y urbanismo de La Rioja, el Tribunal, en el ATC 251/2009, de 13 de octubre, declara su inadmisión al considerarlo notoriamente infundado. El nuevo precepto excluye el sometimiento a licencia municipal -sustituyéndola por mero informe- de los actos de edificación y uso de suelo y subsuelo correspondientes a obras públicas de interés general de la Comunidad Autónoma, considerando como tales "aquéllas que ésta realice (...) destinadas al desarrollo y ejecución de los instrumentos de ordenación del territorio y a la construcción o acondicionamiento de infraestructuras básicas de uso y dominio público, tales como carreteras, obras hidráulicas, de energía o de transporte, etc". El problema, a juicio de los Ayuntamientos demandantes estribaba en extender la exención -habitual en el caso de las obras de infraestructuras- a toda obra de desarrollo y ejecución de los instrumentos de ordenación del territorio, lo que a su entender equivale a convertir la excepción de la licencia en la regla general. El razonamiento del Tribunal -con el que puede concordarse perfectamente sin que por ello se desvirtúe la tesis que aquí queremos demostrar- examina el conjunto de instrumentos de ordenación del territorio previstos en la legislación urbanística riojana y concluye que en el diseño de todos ellos está presente un claro interés supramunicipal, equiparando sus previsiones sobre la sustitución de licencia por el informe municipal a las contenidas en la legislación del Estado en materia de puertos y aeropuertos de interés general, cuya compatibilidad con el respeto a la autonomía local en cuestiones urbanísticas había declarado el Tribunal en sus SSTC 40/1998 y 204/2002. Por eso el Tribunal considera que el precepto legal riojano, en sí mismo considerado, sin un acto de aplicación que lo concrete, no produce vulneración de la autonomía local y decide la inadmisión a limine litis del conflicto. Pero lo realmente significativo a los efectos de evaluar el conflicto en defensa de la autonomía local desde la perspectiva de su eficacia, que es nuestro propósito, es que, como el propio Tribunal reconoce, no se excluye la posibilidad de que la Comunidad Autónoma de La Rioja, basándose en el nuevo precepto, decida considerar de interés general obras que realmente no revisten tal carácter, pero "Solamente en relación con una obra concreta podrá valorarse si la competencia autonómica se ha mantenido dentro de los límites que le son propios, (...) cuestión que no puede ser valorada en esta sede, ya que dicha tarea está encomendada a los tribunales ordinarios”"15. En definitiva, la ley por sí misma no vulnera la autonomía local,

15 ATC 251/2009, FJ 6. Aplica el Tribunal la doctrina constitucional que excluye los pronunciamientos preventivos sobre interpretaciones posibles de las normas sometidas a la jurisdicción constitucional propuestas por las partes (con cita, por todas, de la STC 172/1992). En todo caso, no estará de más recordar que en muchas ocasiones en este tipo de pronunciamientos del Tribunal Constitucional, que no aceptan los motivos de impugnación de preceptos abstractos porque de su mera lectura no puede concluirse una vulneración de la Constitución, además de admitirse -como hace el ATC 251/2009- que los actos de aplicación de tales preceptos sí pueden producir problemas de constitucionalidad, también se acaba cercenando posibles interpretaciones futuras que se reputan contrarias a la Constitución. Precisamente en el caso resuelto por la STC 172/1992 al que se apela en el auto que ahora comentamos, nuestro custodio constitucional salvó la constitucionalidad de la disposición legal catalana que establecía el deber de información a la Comisión Europea de determinados datos relacionados con residuos industriales "a 
es posible que alguno de sus actos de aplicación futuros lo haga, pero para la defensa de los entes locales frente a tales actos la competente es la jurisdicción contencioso-administrativa, a la que se les remite. En definitiva, si se me permite la licencia metafórica, para matar las moscas que son las obras que realmente no tienen interés general aunque lo proclame la Comunidad, de nada vale el cañón -el conflicto en defensa de la autonomía local-con que la LOTC ha provisto a los Ayuntamientos, que deberán seguir, batiéndose el cobre cuerpo a cuerpo, en la jurisdicción contenciosa. Nuestro viaje acaba otra vez en la línea de salida. QED

Pero es que, incluso cuando los entes locales han superado las dificultades numéricas y procedimentales para interponer el conflicto y podía concluirse que la vulneración de la autonomía local, de verificarse, residía ya en la ley, tampoco el Tribunal Constitucional se ha mostrado demasiado receptivo a las demandas de reparación que se le presentan. Es más, en la segunda y última sentencia recaída hasta el momento en un conflicto local, la STC 47/2008, el Tribunal decide acoger la tesis de la desaparición sobrevenida del objeto del conflicto cuando existía a nuestro juicio, y lo que es verdaderamente importante, a juicio del Magistrado que formuló un voto particular discrepante en este sentido, fundamento bastante para entrar en el fondo del asunto, pues la ley derogada, con toda evidencia, seguía desplegando parcialmente efectos tras su derogación, en un sentido que no garantizaba la posición de los municipios afectados y que el Tribunal tampoco consideró.

El asunto se había iniciado por demanda de los municipios integrantes del área metropolitana de L'Horta, en atención a que en la ley que decretaba su supresión se establecían determinadas previsiones sobre la composición de una suerte de comisión liquidadora, encargada de distribuir los medios que tenía atribuidos. Una ley valenciana posterior, aprobada cuando ya se había presentado el conflicto, vino a derogar expresamente la ley impugnada y el Tribunal concluye que, en consecuencia, debe entenderse extinguida la controversia por desaparición del objeto del conflicto. La decisión del Tribunal aplica la doctrina habitual en los conflictos territoriales, también en los suscitados sub specie legis, conforme a la cual lo procedente en los supuestos de derogación sobrevenida del objeto del proceso es examinar si, a pesar de ello, subsiste o no la controversia competencial, aspecto sobre el que el Tribunal interrogará a las partes antes de resolver. Esta doctrina había sido aplicada ya por el Tribunal al conflicto local en dos ocasiones anteriores, en los AATC 513/2004 y 326/2007. La diferencia estriba en que en ambas resoluciones anteriores, que debemos tomar como precedente, parecía haber resultado decisiva para el Tribunal la aquiescencia de la parte demandante con la desaparición de la controversia ${ }^{16}$. Pero es que, además y con mucha mayor trascendencia -como recuerda el voto particular a la STC 47/2008 ${ }^{17}$-, la disposición adicional tercera de la ley que derogó a la que constituía el objeto del conflicto prevé efectos para el futuro de la normativa que deroga, en relación, precisamente, con las actividades que desarrollaba la comisión mixta liquidadora del área de L'Horta, que era en donde los Ayuntamientos habían identificado la vulneración de su autonomía.

Parece, por lo tanto, que no falta razón al voto del Magistrado discrepante cuando juzga decepcionante el resultado al que llegan sus compañeros del Pleno. Y es que, hubiera de otorgárseles o no finalmente la razón a los demandantes, se vedó la oportunidad de obtener un pronunciamiento de fondo que hubiera contribuido, cualquiera que fuera su sentido, a delimitar más precisamente el contenido de la autonomía local en un sector de competencia tradicional de los entes locales, la gestión del agua, que está conociendo una serie de transformaciones importantes como consecuencia de la introducción de criterios de sostenibilidad -ambiental y económica- en su gestión ${ }^{18}$. La concurrencia de esas competencias locales con las que ostentan las Comunidades Autónomas en la materia, a buen seguro habrá de producir algunas dudas en el reparto de responsabilidades entre las Administraciones implicadas que, tal vez, el Tribunal hubiera podido evitar con un pronunciamiento general dictado desde esas consideraciones actuales ${ }^{19}$.

través de los conductos competentes”, pero dejó claro que esos conductos no podían ser otros que los del Estado, en virtud de su competencia en relaciones internacionales. Es decir, no acogió la tesis de la Abogacía del Estado que solicitaba la declaración de inconstitucionalidad de un precepto autonómico porque en su ambigüedad podía considerarse que vulneraba la competencia estatal, pero lo hizo afirmando una única interpretación posible de la expresión “conductos competentes”, equivalente a conductos estatales, con lo que, materialmente, quedó completamente a salvo la competencia del Estado en la materia controvertida (relaciones con la Comisión Europea) aunque desestimando formalmente su demanda. En el caso que comentamos, las posibles interpretaciones del precepto legal urbanístico vulneradoras de la autonomía local no se ciñen exclusivamente a una, con lo que la satisfacción de los intereses locales en la resolución del Tribunal no es comparable a la que produjo en los intereses estatales la STC 172/1992.

16 “(... teniendo en cuenta que la parte actora sostiene que se ha producido dicha pérdida de objeto, que así lo considera la parte demandada (... )" ATC 513/2004, FJ 2. "Para apreciar tal extremo (se refiere a la extinción de la controversia) (...) resulta necesario partir del dato de si la parte actora (...) ha apreciado tal desaparición del objeto del mismo sin que haya mantenido su interés en la obtención de una respuesta a lo planteado en su escrito de planteamiento del conflicto" ATC 326/2007 FJ 2.

17 Formulado por el Magistrado Jorge Rodríguez-Zapata. El razonamiento a que nos referimos en el texto puede leerse en su punto 3.

18 Un breve resumen del devenir del problema de la gestión del agua a que nos referimos en López Vera, F. (2008), “La gestión del agua en España”. En línea http://www.encuentros-multidisciplinares. org/Revistan²9/Fernando_López_Vera.pdf. Desde una perspectiva más jurídica, Vid., por todos, García Rubio, F. (2010), Régimen jurídico de la gestión del agua: aspectos hidrológicos, organizativos, tributarios, de contratación pública y de responsabilidad ambiental, Madrid, La Ley. El Consultor de los Ayuntamientos y de los Juzgados.

19 La práctica procesal del conflicto local que ya hemos comentado-los AATC 360 a 363/2005-son prueba del evidente interés local pre- 
Descartada, al menos de momento, la utilidad práctica del conflicto en defensa de la autonomía local, se podría decir que su misión, que la verdadera rentabilidad del esfuerzo que se hizo por reformar la Ley Orgánica del Tribunal Constitucional para introducirlo, pertenece al terreno de lo simbólico ${ }^{20}$. Es verdad que la reforma fue una más de un conjunto de modificaciones en la normativa local del Estado que culminó con la ley 57/2003, la que estableció el modelo organizativo de municipios de gran población entre otras cosas, y que ambos configuran dos hitos normativos del pacto local en el Estado. No seré yo quien niegue la virtualidad de las operaciones simbólicas, también en el ámbito del Derecho y, por lo tanto, al menos en este sentido, el conflicto ha servido. Pero reconocerlo no puede hacernos desconocer que hoy por hoy los entes locales siguen teniendo en la jurisdicción contenciosoadministrativa el instrumento principal de defensa frente a los otros poderes territoriales que atenten contra su posición constitucional. No otra cosa se puede concluir de las resoluciones recaídas hasta el momento nacidas del nuevo proceso. En cualquier caso, la posición de lo local en el diseño de la estructura territorial del poder político en España, el peso que se le quiera conferir en la adopción de decisiones y su implementación en el marco del gobierno multinivel es un asunto que, a mi modesto entender, supera con creces el ámbito de una reforma procesal, aunque sea en la esfera constitucional.

\section{DUDAS PROCESALES Y RETOS METAPROCESALES DE LA AUTONOMÍA LOCAL AÚN PENDIENTES}

Cuando en 1999 examinábamos el nuevo proceso constitucional llamábamos la atención sobre el difícil encaje que presentaba en el modelo español de control de la constitucionalidad de la ley que los entes locales pudiesen poner en cuestión este tipo de normas, al no estar enumerados entre los legitimados constitucionalmente en el recurso de inconstitucionalidad, único mecanismo existente de control abstracto de normas con rango de ley. Desde el punto de vista del análisis estático del proceso ese era, precisamente, el más grave problema que presentaba, resuelto por el legislador con un expediente artificial -pero necesario como había señalado en su dictamen el Consejo de Estado- de división de un único proceso en dos, o quizá uno y medio ${ }^{21}$. No parece necesario abundar ahora en una crítica que, aunque conserve su fundamento, no puede reiluminarse a partir del examen de la jurisprudencia recaída hasta el momento, pues, como ya hemos señalado, ninguna de las sentencias que han puesto fin a conflictos en defensa de la autonomía local ha apreciado que exista vulneración de este principio constitucional, con lo que tampoco ha habido lugar a que se ponga en marcha la previsión del art. $75 q u i n q u e s 5$ y 6 LOTC. Se mantiene, por tanto, la duda de cómo resolverá el Tribunal Constitucional lo que para mí es una obviedad: que toda norma con rango de ley que vulnere un principio constitucional (lo que se declara en la primera sentencia) ha de resultar inconstitucional (lo que, a mi juicio pretérito y presente, deberá declarar la segunda). La curiosidad que sentimos quienes hemos ido observando el proceso desde su formulación como proyecto tendrá que esperar a verse satisfecha cuando un legislador algo tosco y un Tribunal con mayor sensibilidad hacia lo local de la demostrada hasta el momento coincidan en la resolución de un conflicto en defensa de la autonomía local. Lo primero, como quedó dicho, no es lo habitual; lo segundo no se vislumbra próximo si atendemos a la práctica jurisprudencial que hemos comentado. Por lo demás, resultan imaginables -aunque sigo creyendo que escasamente defendibles- prácticas elusivas de la necesidad de someter la cuestión sobre la constitucionalidad de la ley a una segunda resolución, como algunos comentaristas apuntaron ya hace tiempo. Queda pues pendiente una duda procesal que solo la práctica futura será capaz de despejar.

Así pues, el conflicto en defensa de la autonomía local no ha sido, de momento, vía procesal para incorporar al acervo jurisprudencial constitucional sobre la autonomía local consideraciones novedosas que hayan ampliado el concepto, al interpretar el postulado constitucional de la garantía institucional de la autonomía local de un modo más amplio (comprensivo de mayores cotas de autogobierno) a la luz de la communis iuris opinio sobre lo que ésta sea. El conflicto, con ser un instrumento jurídicamente poderoso, no ha agotado, ni mucho menos, la problemática del nivel local de gobierno en España. Seguramente porque no lo pretendía, pero lo cierto es que, hoy por hoy, sigue siendo el plano de la política, y el de la legislación sectorial susceptible de plasmar los acuerdos políticos, el terreno que debería abonarse si se desea tomar en serio la potenciación de la función que desarrollan las entidades locales en nuestro sistema de gobierno multinivel. Y es que, si se considera -como es mi caso- que la articulación española de la organización territorial del poder tiene una deuda pendiente con el nivel local de gobierno, que a duras penas se intenta desprender de su identificación como mera administración doblemente

sente en la gestión del agua. Desde luego, semejante circunstancia no es exclusiva del mundo local español, ni tampoco la elevada conflictividad que provoca. Una prueba muy reciente de ello puede verse en el litigio resuelto el pasado 2 de mayo de 2011 por el Tribunal Supremo de los Estados Unidos. Vid. Montana v. Wyoming 563 U. S. (2011), en relación con las apropiaciones de agua del caudal de los ríos que bañan luego el parque nacional Yellowstone.

20 Cfr. Caamaño Domínguez, F. (2009), “Autonomía local y principio de subsidiariedad”, p. 15, En línea: http://www.dpz.es/diputacion/ areas/presidencia/asistencia-municipios/municipia/congreso/ponencias/franciscocaama\%C3\%B1o.pdf, para quien el conflicto está teniendo un "resultado más simbólico que práctico".

21 Cfr. Cabello Fernández, Ma D. (2003), El conflicto en defensa de la autonomía local, Madrid, Thomson-Civitas, pp. 238 y ss., cuyas explicaciones y referencias doctrinales sobre la cuestión se mantienen completamente vigentes actualmente. 
subordinada, al nivel autonómico y estatal, harán falta normas jurídicas que articulen acuerdos políticos para solucionar problemas verdaderos del mundo local, de manera distinta -aunque también más costosa- a como puedan hacerlo las reformas procesales. Desde la creencia que una potenciación del nivel local de gobierno, un verdadero local government, un espacio político local más musculado, si se me permite el símil fisiológico, mejoraría exponencialmente la calidad de nuestra democracia, ya en 1999 parecía a quien suscribe algo desenfocada la pretensión de potenciación de los poderes locales sólo desde la perspectiva del Derecho procesal constitucional, incluso dejando momentáneamente de lado las cuestiones sobre la discutible técnica jurídica con que se abordaba.

En este sentido, varios eran y son los retos metaprocesales pendientes en relación con la manera en que la autonomía local se hace presente en la organización del poder público en España. Su tratamiento pormenorizado sobrepasa con creces las pretensiones de este trabajo ${ }^{22}$, aunque no estará de más, para concluirlo, enumerar algunos de ellos (la estructura de lo local; la financiación local y la articulación de la democracia local), siquiera sea como recordatorio de que la potenciación de lo local, más allá del poderoso simbolismo del proceso aquí estudiado, podría venir de la mano del alcance de algunos de esos, y otros, retos.

A mi juicio, uno de los objetivos necesarios en este terreno es la reformulación de la estructura de lo local en España. Hace tiempo que esa estructura no refleja la realidad social y económica a que debería adaptarse. Inevitablemente, la distinta dimensión y entidad de los más de ocho mil Ayuntamientos españoles juega en contra de un tratamiento jurídicamente uniforme, que empezó a romperse con la estructura organizativa y jurídica de los llamados municipios de gran población a raíz de la ley 57/2003. Pero, desde el punto de vista de la gestión de las competencias e intereses locales, hace mucho que triunfan fórmulas alternativas, que intentan superponerse a la fragmentación territorial, evitando los costes - políticos, o más bien sociológicos- de una reducción del número de municipios clamorosamente necesaria. Me refiero, claro está, a las fórmulas asociativas que vienen funcionando con relativo éxito en muchos lugares de España, organizadas aprovechando las economías de escala que se producen en la gestión de los servicios públicos de titularidad municipal pero dimensión supramunicipal, huyendo de la creación de nuevos entramados políticos -las áreas metropolitanas- que, por lo general, resultan considerablemente menos eficientes. Menor eficiencia del entramado metropolitano en la que tiene mucho que ver que, en muchas ocasiones, las áreas se constituyen (o se aprovecha su constitución, si se quiere ser más indulgente) como una arena política adicional, cabeza de puente para el asalto de las estructuras a las que se superpone (municipios) $o$ a las que se subordina (Comunidades), o viceversa.

Mientras no decida acometerse una reducción drástica del número de municipios -lo que, con toda evidencia, no se hará en un contexto de enfrentamiento partidario cortoplacista, como el devenir autonómico ha demostrado tantas veces- a los Ayuntamientos les quedará la vía supramunicipal para defender la preeminencia del interés local de determinados servicios que, de otra manera, dejarían de poder prestarse, lo que se convertiría en la antesala de la desaparición de su capacidad de decisión en ese terreno. Por lo demás, a los mecanismos de gestión mancomunados entre entes locales (municipales y/o provinciales o insulares) se añaden los entes consorciales con administraciones autonómicas, que vienen rindiendo frutos notables, en particular en lo que se refiere al ejercicio de determinadas competencias de titularidad local que, precisamente por la escasa dimensión de algunos Ayuntamientos, pueden ser gestionadas más eficazmente desde otros ámbitos o en colaboración con estos. Algunos ejemplos en materia de gestión de las facultades locales de inspección y disciplina urbanística por parte de consorcios administrativos, o de competencias en materia de extinción de incendios (tengan o no naturaleza jurídica de consorcio local), a los que los Ayuntamientos se adscriben voluntariamente son, a mi juicio, buena prueba de la existencia de una tendencia a suplir la rigidez con que las normas legales atributivas de competencias someten a la gestión local con fórmulas alternativas, viables, eficientes y eficaces. En estos casos, la directriz ha sido el deseo de facilitar el cumplimiento de las normas jurídicas sobre la obligatoriedad de prestación de los servicios locales al menor coste económico y, a veces, como en el caso del urbanismo, también político, articulando una solución desde la Comunidad Autónoma y/o el Gobierno Provincial y supuesta siempre la adscripción voluntaria de los poderes locales ${ }^{23}$.

En relación con el gobierno de las Provincias, su existencia misma seguirá estando justificada por esa misma atomización municipal cuya inconsistencia suplen y a la que se liga su destino. No tanto porque, como suele decirse sin excesiva reflexión, las Diputaciones carecen de sentido en el marco del Estado Autonómico, cuanto porque

22 La Secretaría de Estado de Cooperación Territorial del entonces Ministerio de Administraciones Públicas auspició la elaboración de una suerte de prontuario de diagnósticos y propuestas de solución de los problemas a que me refiero en el texto -y otros varios- que sigue teniendo, a mi juicio, plena vigencia (pese a no haber estado exento de críticas, en particular por quienes no participaron en su elaboración), es el AA. VV. (2005), Libro Blanco para la reforma del Gobierno Local, Madrid, Ministerio de Administraciones Públicas.

23 Valga, por todos, el ejemplo que representa la Agencia Gallega de Protección de la Legalidad Urbanística (un consorcio público administrativo en realidad), prevista en la legislación gallega desde 2002, y que comenzó a funcionar con la aprobación de sus estatutos por Decreto de la Xunta de Galicia 213/2007, de 31 de octubre. 
dejarán de tenerlo si sus actuales cometidos se encargan a las Administraciones Autonómicas. Pero la desaparición de las Diputaciones -supuesto el cumplimiento de las reservas constitucionales, lo que de por sí parece, hoy por hoy, condenar al fracaso la tentativa- no tendría sentido si no viene acompañada de la reducción drástica del número de municipios, porque suprimir Diputaciones sin alterar el mapa municipal, por muy eficiente que pueda parecer desde el punto de vista de la gestión de la cooperación local, lo que esconde es el cercenamiento de la autonomía municipal. Con frecuencia se olvida, aventuro que interesadamente, que el de las Diputaciones es también autogobierno local, que la labor de auxilio a los Ayuntamientos que se realiza desde la instancia provincial es una fórmula que garantiza en sí misma la autonomía local, pues son representantes locales los que dirigen la entidad provincial. Si, por el contrario, se procediese en primer lugar a reducir el número de municipios, la entidad de los Ayuntamientos resultantes permitiría la autogestión de competencias que actualmente, por el escaso peso específico de los micromunicipios, se confían a las entidades locales provinciales. El cambio supondría una transferencia desde lo local (Diputación) a lo local (Ayuntamientos más grandes) y solo el residuo de la actividad provincial actual no susceptible de gestionarse desde los nuevos Ayuntamientos (por ejemplo, la red provincial de carreteras), se encomendaría a las Administraciones autonómicas. De este modo se mejoraría en la gestión de competencias locales desde el ámbito local, aunque éste tuviese una estructura diferente a la actual. Pero una reestructuración del mapa local español que consistiera en la desaparición de las Diputaciones y el encargo de las funciones que actualmente ejercen a las Administraciones Autonómicas sin alterar -a la baja- el número de Ayuntamientos constituiría un atentado a la autonomía local que, aunque pudiera llegar a cumplir formalmente los costosos requerimientos constitucionales, iría en contra del modo en que esta se entiende actualmente.

Otro de los retos pendientes a que nos referíamos y que enunciaremos solamente es el de la financiación local. Que la Constitución proclamara en el artículo 142 que las haciendas locales deberían disponer de los recursos suficientes para el desempeño de sus funciones no ha garantizado una auténtica autonomía financiera local, no tanto por el incumplimiento del principio de suficiencia en sí -que también-, sino porque su cumplimiento se ha verificado a través de la aportaciones del Estado y las Comunidades Autónomas instrumentadas por medio de subvenciones en muchos casos condicionadas, es decir, con escaso respeto a la autonomía local en lo que ésta tiene de decidir, con arreglo a la ley pero libremente, el destino de los fondos públicos de que dispone. Tampoco a esta realidad es ajena, por otra parte, la inadecuada estructura municipal española que hemos comentado. Por un lado, esa estructura provoca ineficiencias en la financiación de servicios que ya hemos señalado y facilita la competencia fiscal entre municipios, que no pueden gravar con impuestos a no residentes que, sin embargo, son usuarios diarios de los bienes y servicios de titularidad municipal. Las facilidades al tránsito que generan las modernas vías de comunicación (carreteras y ferrocarriles) convierten en ridículo el tamaño de los términos municipales en la misma medida que favorecen prácticas fiscales elusivas fomentadas por poderes locales con escasa voluntad cooperativa. Por otro lado, allí donde las circunstancias no favorecen la movilidad de contribuyentes (por inexistencia de parque de viviendas u otras causas) la inhibición fiscal de muchos pequeños municipios se explica también porque algunos gobernantes locales han preferido no pagar el coste de oportunidad política de grabar actividades y servicios con impuestos y tasas justas y abrazar, para compensar financieramente su irresponsable proceder, el mecanismo de la subvención. Ésta, desde el punto de vista de la autonomía local, tiene como desventaja la limitación de la capacidad de decisión de gasto de los entes locales y, además, aniquila la tan necesaria, a mi entender, autoordenación estratégica del gasto público, al no controlar los entes locales ni el régimen jurídico, ni la periodicidad de instrumentos de financiación cuyo diseño e implementación corresponden por entero al Estado o a las Comunidades Autónomas. El riesgo para la autonomía financiera local procede del importante peso específico relativo que sobre el conjunto de los ingresos municipales adquieren las subvenciones condicionadas, un aspecto que la jurisprudencia constitucional ya puso de manifiesto ${ }^{24}$, al llamar la atención sobre la naturaleza de financiación complementaria que deben tener este tipo de ingresos, yuxtapuestos a una financiación ordinaria y no condicionada que es de la que deben disponer con libertad y bajo su responsabilidad los entes locales para hacer frente a los servicios públicos de su competencia.

El tercero de los retos pendientes que trascienden lo procesal en relación con la autonomía local que hemos enunciado es el de la mejor articulación democrática de los entes locales, muy particularmente de los municipios españoles. Decía Alexis de Tocqueville, tras examinar el funcionamiento de los Gobiernos locales de Nueva Inglaterra, que es posible la existencia de pueblos libres que carezcan de instituciones locales fuertes, pero que lo que distingue a los pueblos que reconocen fortaleza al poder local es que tienen, además, espíritu libre. A nadie se le escapa que la grandeza del autogobierno local reside en la proximidad, problemas locales a los que se provee desde las instituciones locales, conformadas democráticamente. Terreno abonado, así pues, para los lugares comunes habituales -aunque no por ello falsos ${ }^{25}$ - que identifican a las instituciones locales con una suerte de escuela

24 Cfr., por todas, SSTC 237/1992 y 109/1998.

$25 \mathrm{Y}$, desde luego, tampoco exclusivos de nuestro país. Una relativamente reciente demanda académica de fortalecimiento de la de- 
del ejercicio del poder político, primer paso natural de las vocaciones políticas, caldo de cultivo para las fórmulas participativas y cooperativas del ejercicio del poder, etc. y, por lo mismo, para la aparición de local evils, (utilizando la expresión que se acuñara en la jurisprudencia del Tribunal Supremo de los Estados Unidos), de distorsiones del funcionamiento de la democracia, que la pervierten con mayor facilidad también donde el universo político es más pequeño y las posibilidades de triunfo también mayores. No hará falta poner de manifiesto la vinculación que en el imaginario colectivo ${ }^{26}$ existe entre el ejercicio de algunas competencias típicamente locales -como las que afectan a la materia de urbanismo- y el fenómeno de la corrupción. Y así, el primer nivel del Gobierno democrático se transforma, a veces, en el primer paso de la ruina de la democracia.

Evitar este complejo de odiosos fenómenos, que provocan un daño concreto a lo público distinto en cada supuesto y un daño genérico común a todos ellos que incrementa en el sumatorio del descrédito en la articulación de nuestro Estado Democrático es una tarea de amplio espectro, que abarca, a mi juicio, desde la pedagogía política hasta el Derecho Penal, pasando, por supuesto, por el autocontrol en los partidos políticos en la selección de sus cuadros y candidaturas y, en el funcionamiento institucional, a la legislación electoral.

En este último sentido, debemos felicitarnos por un paso dado muy recientemente. Nos referimos a la modificación que, por Ley Orgánica 2/2011, de 28 de enero, ha introducido algunos cambios en las mayorías requeridas para la presentación de la moción de censura al Alcalde. La reforma, como ha sucedido otras veces aunque no siempre con el éxito apetecido, tiene como finalidad desincentivar la labilidad de los compromisos políticos en el ámbito local, dificultando la presentación de mociones de censura. Con la nueva redacción dada al artículo 197.1 de la Ley Orgánica de Régimen Electoral General, la presentación de la moción de censura requiere la firma de la mayoría absoluta del número de miembros de Derecho de la Corporación, en lugar de su tercera parte como hasta ahora. El notable incremento del requisito del número de firmantes -equiparado al exigido para aprobar la moción ${ }^{27}$ - es aún mayor para los casos en que concurran dos circunstancias habituales en la vida política municipal: que la moción venga firmada por Concejales que pertenezcan o hayan pertenecido al grupo político del Alcalde o que la moción venga firmada por Concejales que no pertenecen al mismo grupo político municipal al que se adscribieron al tomar posesión de su acta. En estos dos supuestos, los proponentes deben ser al menos la mayoría absoluta incrementada en tantos Concejales como firmantes se hallen en esta situación.

La confesada finalidad de la norma no es otra que dificultar las operaciones de transfuguismo y contribuir así a poner fin a una de las malas prácticas de la política local española que más ha contribuido a su descrédito. Los Gobiernos municipales conformados por un mismo partido político verán así fortalecida su posición, aunque la norma no alcanzará a dar estabilidad a los ejecutivos de coalición, pues los Concejales que no pertenezcan al mismo grupo político del Alcalde y no hayan cambiado de grupo desde el inicio de su mandato, por más que puedan formar parte del Gobierno municipal, sí podrán contribuir a conformar la mayoría absoluta necesaria para proponer válidamente la moción.

En un contexto en el que estos retos que solo hemos apuntado y algunas otras dificultades que acompañan al Gobierno local puedan superarse, tal vez el conflicto en defensa de la autonomía local pueda figurar como colofón, como instrumento procesal de cierre de las garantías de un autogobierno local fundado sobre nociones y principios que, figurando en la Constitución y en los acuerdos internacionales sobre la materia ratificados por España, aún tienen por delante mucho recorrido para hacerse plenamente reales y efectivos.

mocracia desde la potenciación del nivel local de gobierno en el Reino Unido puede verse en Bailey, S. y Elliott, M. (2009), “Taking Local Government Seriously: Democracy, Autonomy and the Constitution”, Cambridge Law Journal, (vol 68,2), pp. 436-472.

26 Como las prácticas de la corrupción no pueden ser ajenas a la situación económica, no sorprenderá que, entre las conclusiones del informe global sobre la corrupción del año 2010 que realiza la organización no gubernamental Transparency International, y en relación con España, se haya detectado un descenso en la problemática de la corrupción vinculada al urbanismo, sustituida por prácticas corruptas relacionadas con las infraestructuras de energías renovables (habiéndose detectado fraudes en más de 4000 instalaciones solares fotovoltaicas, en un 13\% de parques españoles). Vid. Calleja, T. (2010) “La incentivación de la energía solar ¿puede ser una invitación al fraude?”, en Transparency International Informe Global 2010 sobre la corrupción. En línea http://www.transparency.org/content/download/60588/970878/ Global_Corruption_Report_Climate_Change_Spanish. El informe completo y desglosado puede leerse en la web de la organización en España: http://www.transparencia.org.es/INFORME\%20GLOBAL\%202010/INDICE\%20INFORME\%20GLOBAL\%202010.htm, de él cabe destacar que la percepción, en España y fuera de ella, es el aumento de las prácticas corruptas y que las instituciones identificadas como más corruptas son los partidos políticos.

27 Una suposición, en realidad, pues el número Cincuenta y siete del artículo único de la Ley Orgánica 2/2011 ha empleado, para articular la reforma del texto de la LOREG, la habitual técnica de disponer el modo en que queda redactado el precepto legal -que preexistía-y ha olvidado incluir (indicando que no variaba su contenido) el apartado identificado con la letra f) del artículo 197, con lo que bien podría entenderse que, no existiendo (pues se ha obviado) previsión expresa sobre la mayoría requerida para la aprobación de la moción de censura, lo requerido es la simple mayoría de votos de los presentes el día de la votación. El error -que es constatable en la consulta de las bases de datos oficiales y venales, pero que desaparece cuando se consultan versiones consolidadas, incluida la que facilita la propia Agencia del Boletín Oficial del Estado- debería ser corregido formalmente para evitar consecuencias tan absurdas como seguramente nunca queridas por el legislador. 


\section{BIBLIOGRAFÍA CITADA}

AA. VV. (2005), Libro Blanco para la reforma del Gobierno Local, Madrid, Ministerio de Administraciones Públicas.

Bailey, S. y Elliott, M. (2009), “Taking Local Government Seriously: Democracy, Autonomy and the Constitution”, Cambridge Law Journal, (vol. 68, 2), pp. 436-472.

Calleja, T. (2010) “La incentivación de la energía solar ¿puede ser una invitación al fraude?”, en Transparency International Informe Global 2010 sobre la corrupción. En línea http://www.transparency.org/content/download/60588/970878/Global_Corruption_Report_Climate_Change_Spanish.

Caamaño Domínguez, F. (2009), “Autonomía local y principio de subsidiariedad”. En línea http://www.dpz.es/ diputacion/areas/presidencia/asistencia-municipios/municipia/congreso/ponencias/francisco-caama\%C3\%B10.pdf

Cabello Fernández, Mª D. (2003), El conflicto en defensa de la autonomía local, Madrid, Thomson-Civitas.

Font i Llovet, T. (1997) “El recurso de protección contra la autonomía local” en Defensa de la autonomía local ante el Tribunal Constitucional, Madrid, Ministerio de Administraciones Públicas-Instituto Nacional de Administración Pública.

García Roca, J. (2000), “El nuevo conflicto en defensa de la autonomía local”, Justicia Administrativa (nºxtraordinario "La reforma del régimen local”), pp. 5-32.

García Rubio, F. (2010), Régimen jurídico de la gestión del agua: aspectos hidrológicos, organizativos, tributarios, de contratación pública y de responsabilidad ambiental, Madrid, La Ley. El Consultor de los Ayuntamientos y de los Juzgados.

Hernández Lafuente, A (1995) Estatutos de Autonomía para Ceuta y Melilla, Málaga Algazara.

López Vera, F. (2008) “La gestión del agua en España”, En línea http://www.encuentros-multidisciplinares. org/Revistan²9/Fernando_López_Vera.pdf.

Montilla Martos, J. A. (1994) Las leyes singulares en el ordenamiento constitucional español, Madrid, Civitas

Naranjo de la Cruz, R. (2003) El proceso constitucional para la protección de la autonomía local en España y Alemania, Madrid, INAP-Diputación Provincial de Málaga.

Pérez Tremps, P (1998) La defensa de la autonomía local ante el Tribunal Constitucional, Madrid, Marcial Pons.

Porras Ramírez, J. M. (2001) El conflicto en defensa de la autonomía local ante el Tribunal Constitucional, Madrid, Civitas.

Pulido Quecedo, M. (2010), “Normas forales vascas”, Actualidad Jurídica Aranzadi (798), pp. 3-4.

Roura Gómez, S. (1999) “El conflicto en defensa de la autonomía local”, Revista Vasca de Administración Pública, (55), 227-251. (2001) “El conflicto en defensa de la autonomía local en España”, Revista Jurídica del Perú, (Año LI, 20) 1-21.

Ruipérez Alamillo, J (1991) Formación y determinación de las Comunidades Autónomas en el Ordenamiento Constitucional español, Madrid, Tecnos, 2. ${ }^{a}$ ed.

Sánchez Morón, M. (2001), “De los conflictos en defensa de la autonomía local” en Requejo Pagés, J. L. (coord.), Comentarios a la Ley Orgánica del Tribunal Constitucional, Madrid, Tribunal Constitucional Transparency International (2010), Informe global sobre la corrupción. En línea http:// www.transparencia.org.es/INFORME\%20 GLOBAL\%202010/INDICE\%2OINFORME\%20GLOBAL\%202010.htm 
